\title{
Determining the prevalence of infectious pancreatic necrosis virus in asymptomatic brook trout Salvelinus fontinalis: a study of clinical samples and processing methods
}

\author{
P. E. McAllister, W. B. Schill, W. J. Owens, D. L. Hodge \\ U.S. Fish and Wildlife Service, National Fish Health Research Laboratory, Box 700, Kearneysville, \\ West Virginia 25430, USA
}

\begin{abstract}
Fluid and tissue specimens taken from brook trout by destructive and nondestructive methods were processed several ways to determine the suitability of the samples and the sensitıvity and efficiency of the processing methods for determining the prevalence of infectious pancreatic necrosis virus (IPNV). For detecting viral infectivity, the cell fraction of ovarian fluid, kidney + spleen samples, and pyloric caeca samples were essentially indistinguishable and gave the highest level of sensitivity with the supernatant fraction of ovarian fluid being the next highest. The white blood cell fraction was variable in delineating virus carriers, and virus titers of white cell fractions were several $\log _{10} \operatorname{less}$ than ovarian fluid or tissues. The plasma fraction was not suitable for detecting IPNV. The choice of clinical sample and processing method affected detection of viral infectivity. Ovarian fluid samples had a tendency to show autointerference and inherent inhibition of viral infectivity, but little toxicity. Samples of kidney + spleen showed higher inherent inhibition and toxicity, but little autointerference. Samples of pyloric caeca showed the highest degree of toxicity, but little autointerference or inhibition of infectivity.
\end{abstract}

\section{INTRODUCTION}

In the United States, current inspection procedures for the detection of infectious pancreatic necrosis virus (IPNV) in asymptomatic fish require the sacrifice of a portion of the fish population to collect samples of kidney and spleen for virological examination (Amos 1985). Sex products, such as milt and the fluid that is expressed with eggs at spawning (ovarian or coelomic fluid), and other nondestructive samples (e.g. blood, feces, gill arches, and mucus) are not acceptable alternatives to tissue sampling (Amos 1985). In addition, assays for antibody to IPNV are not acceptable as a nondestructive method for health surveillance. The practice of destructive sampling can be economicaily and logistically expensive to producers, detrimental to genetic diversity of broodstock if the number of broodfish is limited, and bio-politically unpalatable if the species is the focus of restoration. Fish culturists and program managers, while concerned about producing healthy fish, are increasingly interested in applying nondestructive sampling methods for health inspections. Similarly, fish health diagnosticians are looking for sampling and processing methods that are rapid, sensitive, specific, and reliable.

Wolf et al. (1963) were the first to demonstrate that IPNV could be detected in ovarian fluid, and McAllister et al. (1987) showed that the cell and particulate components of ovarian fluid were particularly useful for detection of IPNV in asymptomatic fish. Swanson \& Gillespie (1982) and Yu et al. (1982) suggested that blood and blood fractions can be used for detection of IPNV in carrier and in experimentally infected fish, and Agius et al. $(1982,1983)$ and Hedrick et al. (1986) evaluated different methods for processing tissue samples.

In the present study, we compared the suitability of various fluid and tissue specimens and the sensitivity 
and efficiency of several sample processing methods for monitoring the prevalence of IPNV in asymptomatic, virus-carrier broodstock.

\section{MATERIALS AND METHODS}

Cell culture. Chinook salmon embryo (CHSE-214) cells (Lannan et al, 1984) were grown at $18^{\circ} \mathrm{C}$ in Eagle's minimum essential medium (MEM) containing $10 \%$ fetal bovine serum and either 100 IU penicillin $\mathrm{ml}^{-1}$ and $100 \mu \mathrm{g}$ streptomycin $\mathrm{ml}^{-1}$ or $100 \mu \mathrm{g}$ gentamycin $\mathrm{ml}^{-1}$. For viral infectivity assays, monolayer cultures of CHSE-214 cells were prepared in 8-well plates. Virus was titered by plaque assay as described by vivif \& Quimby (1973), anc ì̉e iiter was expressed as plaque forming units per $\mathrm{ml}$ (PFU $\mathrm{ml}^{-1}$ ). Virus was identified as IPNV by dot blot enzyme-linked immunosorbent assay (McAllister \& Schill 1986). The IPNV was serotype VR-299.

Fish. Two stocks of IPNV-carrier brook trout Salvelinus fontinalis were used for our studies - the fish were survivors of natural IPNV infections. One stock was 2-yr-old production brood fish held at a state hatchery. The second stock was 4 -yr-old brood fish held since fingerlings at the National Fish Health Research Laboratory. Both fish stocks were held in 10 to $12^{\circ} \mathrm{C}$ spring water.

Clinical samples and sample processing. For the 4yr-old fish, ovarian fluid, blood, kidneys (posterior half), spleen, and pyloric caeca were collected at spawning. For the 2 -yr-old fish, ovarian fluid and blood wele collected at spawning and the fish were coldbranded for individual identification. Then at $4 \mathrm{mo}$

Table 1. Salvelinus fontinalis. Comparison of destructive and nondestructive sampling and sample processing procedures for detection of IPNV in natural.ly infected brook trout

\begin{tabular}{|c|c|c|c|c|}
\hline Sample/Method & Prevalence & Titer range ${ }^{\mathrm{d}}$ & Median titer ${ }^{d}$ & Mode titer \\
\hline \multicolumn{5}{|c|}{ A. 4-yr-old brook trout: specimens collected at spawning } \\
\hline \multicolumn{5}{|l|}{ Ovarian fluid } \\
\hline Supernatant & $18 / 28 \quad(64.3 \%)$ & $N V D-10^{6.2}$ & $10^{24}$ & NVD \\
\hline Pellet (sonic) & $28 / 28(100.0 \%)$ & $10^{0.0}-10^{7.6}$ & $10^{52}$ & $10^{5.3}$ \\
\hline \multicolumn{5}{|l|}{ Kidney + spleen } \\
\hline Homogenization & $27 / 28 \quad(96.4 \%)$ & NVD $-10^{5}$ & $10^{44}$ & $10^{54}$ \\
\hline Trypsinization & $26 / 28 \quad(92.9 \%)$ & NVD $-10^{6.2}$ & $10^{5.1}$ & $10^{54}$ \\
\hline \multicolumn{5}{|l|}{ Pyloric raeca } \\
\hline Homogenization & $25 / 28 \quad(89.3 \%)$ & NVD $-10^{7.0}$ & $10^{5.0}$ & $10^{54}$ \\
\hline Trypsinization & $24 / 28 \quad(85.7 \%)$ & NVD $-10^{6.9}$ & $10^{5.5}$ & $10^{54}$ \\
\hline \multicolumn{5}{|l|}{ Blood } \\
\hline Plasma & $0 / 28 \quad(0.0 \%)$ & NVD & NVD & NVD \\
\hline White cells & $16 / 28 \quad(57.1 \%)$ & NVD $-10^{2.0}$ & $10^{0.4}$ & NVD \\
\hline \multicolumn{5}{|c|}{$\begin{array}{l}\text { B. } 2 \text {-yr-old brook trout: } \\
\text { Specimens collected at spawning }\end{array}$} \\
\hline \multicolumn{5}{|l|}{ Ovarian fluid } \\
\hline Supernatant & $25 / 28 \quad(89.3 \%)$ & NVD $-10^{4.5}$ & $10^{3.9}$ & $10^{0.7,13,4.4 .67}$ \\
\hline Pellet (sonic) & $27 / 28 \quad(96.4 \%)$ & NVD $-10^{76}$ & $10^{4.0}$ & $10^{25.76}$ \\
\hline \multicolumn{5}{|l|}{ Blood } \\
\hline Plasma & $0 / 28 \quad(0.0 \%)$ & NVD & NVD & NVD \\
\hline White cells & $2 / 28 \quad(7.1 \%)$ & NVD $-10^{12}$ & NVD & NVD \\
\hline \multicolumn{5}{|c|}{ Specimens collected 4 mo post-spawning } \\
\hline \multicolumn{5}{|l|}{ Kidney + spleen } \\
\hline Homogenization & $26 / 28 \quad(92.9 \%)$ & NVD $-10^{5.0}$ & $10^{3.4}$ & $10^{2 \cdot 3,3.8}$ \\
\hline Trypsinization & $27 / 28 \quad(96.4 \%)$ & NVD - $10^{43}$ & $10^{3.2}$ & $10^{2.7 .33 .4 .2}$ \\
\hline \multicolumn{5}{|l|}{ Pyloric caeca } \\
\hline Homogenization & $24 / 28 \quad(85.7 \%)$ & NVD $-10^{5.2}$ & $10^{4.6}$ & $1.0^{4.4 .4 .8}$ \\
\hline Trypsinization & $22 / 28 \quad(78.6 \%)$ & NVD $-10^{49}$ & $10^{40}$ & $10^{4.4}$ \\
\hline \multicolumn{5}{|l|}{ Blood } \\
\hline Plasma & $2 / 28 \quad(7.1 \%)$ & NVD $-10^{12}$ & NVD & NVD \\
\hline White cells & $3 / 28 \quad(10.7 \%)$ & NVD $-10^{19}$ & NVD & NVD \\
\hline
\end{tabular}


after spawning, blood, kidneys (posterior half), spleen, and pyloric caeca were taken. In all cases, clinical specimens were held on ice and assayed for viral infectivity within 1 to $3 \mathrm{~h}$ of collection. Processed specimens or fractions thereof were diluted in $0.1 \mathrm{M}$ phosphate buffered saline (pH 7.2; PBS) and assayed for infectious virus. Sample dilutions were plated in duplicate, and replicate assays were performed. Ovarian fluid samples were processed as described by McAllister et al. (1987), and infectivity assays were performed on the supernatant fluid as well as on sonicated and on homogenized cell fractions of the ovarian fluid pellet. Pooled kidney + spleen samples and pyloric caeca samples were divided into 3 aliquots and processed for infectivity assay. One aliquot was processed by homogenization with mortar and pestle (Amos 1985, Hedrick et al. 1986) and the other 2 aliquots by trypsinization (Agius et al. 1982, 1983) with further processing of 1 aliquot of the trypsinized product by homogenization and the other by sonication (McAllister et al. 1987). Whole blood was collected in an equal volume of $0.034 \mathrm{M}$ sodium citrate in $0.05 \mathrm{M}$ potassium phosphate buffer ( $\mathrm{pH} \mathrm{7.2).} \mathrm{The} \mathrm{white} \mathrm{cell} \mathrm{and} \mathrm{plasma} \mathrm{frac-}$ tions were collected from Percoll- $0.75 \mathrm{M}$ sucrose gradients centrifuged at $700 \times \mathrm{g}$ for $15 \mathrm{~min}$ at $10^{\circ} \mathrm{C}$. The white cell fraction was treated by sonication (McAllister et al. 1987) and then assayed for viral infectivity. The plasma fraction was assayed for viral infectivity without further processing.

\section{RESULTS}

\section{Assays of 4-yr-old brook trout}

The ovarian fluid pellet gave the highest level of detection (prevalence $=100 \%$ ) with the kidney + spleen pool and the pyloric caeca also giving high levels of detection (prevalence $=85$ to $96 \%$ (Table $1 \mathrm{~A})$. The highest infectivity titers occurred in the ovarian fluid pellet although the median and mode titer values for ovarian fluid pellet, kidney + spleen pool and pyloric caeca were roughly equivalent. Lower levels of detection occurred with the ovarian fluid supernatant (prevalence $=64 \%$ ) and the white cell blood fraction (prevalence $=57 \%$ ), and their median and mode virus titer values were also much lower. No viral infectivity was detected in plasma fractions. Those fish in which ovarian fluid pellet samples had virus titers of $10^{\circ}$ to $10^{3} \mathrm{PFU} \mathrm{ml} \mathrm{m}^{-1}$ were found to be virus-negative using samples of ovarian fluid supernatant, kidney + spleen pool or pyloric caeca

In addition to sonicating the ovarian fluid pellet, we also processed the pellet fraction by homogenization (prevalence $=89 \%$ ) and by treating the pellet for $10 \mathrm{~s}$ in a contact lens ultrasonic cleaner bath (prevalence = $87 \%$ ). The prevalence values compared favorably with those for tissue samples. The virus titers of homogenized pellets were about 2 -fold lower and those of the lens cleaner bath-treated pellet were about 4-fold lower than the sonicated pellet (data not shown). The titers of the ovarian fluid pellet were greater than titers for ovarian fluid supernatant or for tissue samples regardless of the processing method.

Prevalence was higher with the pooled kidney + spleen samples than with pyloric caeca. Processing tissues by homogenization or trypsinization did not significantly affect prevalence, but somewhat higher infectivity titers were seen in samples processed by the trypsinization procedure, although the mode titer values were nearly the same. Sonicated trypsinized tissue had a slightly higher virus titer than homogenized trypsinized tissue, but virus prevalence was identical by both methods (data not shown).

\section{Assays of 2-yr-old brook trout}

In the study with 2-yr-old brook trout, sex products and blood were collected at spawning and then 4 mo later tissues and blood were collected. As with the 4-yr-old brook trout, the ovarian fluid samples gave the highest virus titers (Table $1 \mathrm{~B}$ ). Virus prevalence in ovarian fluid pellet (96\%) was comparable to that in kidney + spleen pool (92 to $96 \%$ ) while prevalence was lower with the ovarian fluid supernatant (89\%) and pyloric caeca ( 78 to $85 \%$ ). The median virus titers of the ovarian fluid and tissue samples were quite similar, but multi-modal titer distribution was seen. Virus was detected in some blood fractions. Virus prevalence in white cells was 7 to $10 \%$ and in plasma was 0 to $7 \%$, but the titers were much lower than those from sex products and tissues.

In this younger population of fish, the difference in virus prevalence and titer between ovarian fluid supernatant and pellet samples was small, but those fish in which ovarian fluid pellet samples had virus titers of $10^{0}$ to $10^{1} \mathrm{PFU} \mathrm{ml} \mathrm{m}^{-1}$ were found to be virus-negative using samples of ovarian fluid supernatant. Prevalence was higher in kidney + spleen pool samples than in pyloric caeca samples, but the prevalence within tissue sample groups was not appreciably affected by processing methodology.

\section{Factors affecting interpretation of infectivity assays}

The ability to recognize and measure viral infectivity was hampered by autointerference, inherent inhibition of infectivity, and toxicity (Table 2). 
Table 2. Interpretation of infectivity assays: effects of sample type and sample processing procedures. Inhibit: inhibition of viral infectivity

\begin{tabular}{|c|c|c|c|c|}
\hline Sample/Method & Prevalence $^{d}$ & Autointerence & Inhibit & Toxicity \\
\hline \multicolumn{5}{|l|}{ Ovarian fluid } \\
\hline Supernatant & $43 / 56(76.8 \%)$ & $4 / 56 \quad(7.1 \%)$ & $12 / 56(21.4 \%)$ & $(0.0 \%)$ \\
\hline Pellet (sonic) & $55 / 56(98.2 \%)$ & $16 / 56(28.6 \%)$ & $0 / 56 \quad(0.0 \%)$ & $1 / 56 \quad(1.8 \%)$ \\
\hline \multicolumn{5}{|l|}{ Kidney + spleen } \\
\hline Homogenization & $53 / 56(94.6 \%)$ & $0 / 56 \quad(0.0 \%)$ & $22 / 56(39.3 \%)$ & $5 / 56 \quad(8.9 \%)$ \\
\hline Trypsinization & $53 / 56(94.6 \%)$ & $0 / 56 \quad(0.0 \%)$ & $1 / 56 \quad(1.8 \%)$ & $12 / 56 \quad(21.4 \%)$ \\
\hline \multicolumn{5}{|l|}{ Pyloric caeca } \\
\hline Homogenization & $49 / 56(87.5 \%)$ & $0 / 56 \quad(0.0 \%)$ & $0 / 56 \quad(0.0 \%)$ & $56 / 56(100.0 \%)$ \\
\hline Trypsinization & $46 / 56(82.1 \%)$ & $0 / 56 \quad(0.0 \%)$ & $0 / 56 \quad(0.0 \%)$ & $42 / 56 \quad(75.0 \%)$ \\
\hline \multicolumn{5}{|l|}{ Biouri } \\
\hline Plasma & $2 / 84 \quad(2.4 \%)$ & $0 / 84 \quad(0.0 \%)$ & $0 / 84 \quad\{0.0 \%\}$ & $23 / 84 \quad(27.4 \%)$ \\
\hline White cells & $21 / 84(25.0 \%)$ & $0 / 84 \quad(0.0 \%)$ & $0 / 84 \quad(0.0 \%)$ & $2 / 84 \quad(2.4 \%)$ \\
\hline
\end{tabular}

Autointerference, seen as a cell sheet ostensibly unaffected by viral infectivity, occurred exclusively with ovarian fluid samples and at greatest frequency with ovarian fluid pellet samples. Autointerference occurred in samples with a virus titer greater than $10^{6}$ PFU ml-1 although it was seen in several instances when the titer was $10^{5} \mathrm{PFU} \mathrm{ml} \mathrm{ml}^{-1}$ Autointerference effects were evident in cells inoculated with undiluted and 1:10 dilutions of sample and occasionally at 1.100 dilutions of sample.

Inherent inhibition of infectivity appeared as aberrant relationships between plaque numbers and serial 10 -fold dilutions of sample. Inhibition of infectivity occurred with ovarian fluid supernatant samples and with kidney + spleen pool samples processed by homogenization and was evident in cells inoculated with undiluted, $1 \cdot 10$, and 1:100 dilutions of sample.

Toxicity, the partial or wholesale destruction of expanses of cell monolayer, occurred at high frequency in pyloric caeca ( 75 to $100 \%$ ), at intermediate frequency in kidney + spleen pool processed by trypsinization $(21 \%)$, at variable frequency in plasma blood fractions, and at low or little frequency with other clinical samples and processing methods. With pyloric caeca, the highest frequency of toxicity $(100 \%)$ occurred in samples processed by homogenization. High frequency toxicity $(78 \%)$ occurred in plasma fractions from blood collected at 4 mo after spawning, but little toxicity occurred in plasma fractions from blood collected at spawning. Removing the inoculum at the end of the adsorption period ( 45 to $60 \mathrm{~min}$ ) or at earlier times did not reduce toxicity (data not shown).

\section{DISCUSSION}

Our results suggest that ovarian fluid samples can be used as a nondestructive sample to detect IPNV in asymptomatic fish. Furthermore, we found the pellet fraction of ovarian fluid provided a level of detection equal or superior to that from tissue samples. Prevalence levels with kidney + spleen versus pyloric caeca, whether taken at spawning or at 4 mo postspawning, were not appreciably different, but were usually higher with kidney + spleen samples as previously reported by Agius et al. $(1982,1983)$. High virus prevalence was found in sex products and tissues from both 2-yr-old and 4-yr-old fish, a contrast to the observation of decreasing prevalence with age noted by Yamamoto (1975a) and Yamamoto \& Kilistoff (1979) for fish that were planted in lakes and the more rapid decline of IPNV prevalence in fish in a hatchery (Yamamoto 1975b). The differences in these observations may be related to variables associated with culture conditions.

Our tests of blood fractions showed them to be unreliable as samples for detecting virus in asymptomatic fish. In general, negligible levels of virus and few virus-positive fish were detected in assays of plasma from spawning and post-spawning fish. Our results with the plasma fraction corresponded with the results of Yu et al. (1982) and Swanson \& Gillespie (1982) who also found that, at best, virus was found infrequently in plasma in both naturally and experimentally infected fish. The results from white cell blood fractions were highly variable compared to those from sex products and tissues. Our findings with white cells differed from 
those of Yu et al. (1982) who recovered IPNV consis tently from the leucocytes of asymptomatic 1-yr-old brook trout and 3- to 4-yr-old rainbow trout Oncorhynchus mykiss. Similarly, Swanson \& Gillespie (1982) recovered IPNV from white cells for up to $40 \mathrm{~d}$ after experimental infection, but found that thereafter virus localized in tissues, particularly the kidneys. In both the Yu et al. (1982) and Swanson \& Gillespie (1982) studies, the leucocytes were assayed by co-cultivation; whereas, in our assays leucocytes were sonicated in the same manner as ovarian fluid pellets to release cell-associated virus.

We found that the manner in which ovarian fluid pellet and tissue samples were processed did not appreciably affect prevalence, but did affect the perceived titer of individual samples, particularly detection of virus at low levels of infectivity. Overall, higher titer values were recorded when a sonication step was included in sample processing, which agrees with a similar observation made by Agius et al. (1983). We found that processing tissues by homogenization or trypsinization and further processing of trypsinized tissue by homogenization or sonication gave essentially equivalent prevalence. Similarly, processing the ovarian fluid pellet by sonication, homogenization or low power ultrasonic bath gave equivalent prevalence, but lower titer values were seen when the ovarian fluid pellet was processed by homogenization or low power ultrasonic bath

We found that the sample processing method could affect interpretation of assay results. With ovarian fluid, cell cultures should be inoculated with low dilutions of sample (undiluted to $1: 10$ ) to detect low levels of virus and also with higher dilutions $(1: 100$ to $1: 1000)$ to detect levels of virus that could be masked by autointerference or by factors inherent to the sample that inhibit viral infectivity. Autointerference occurred most often in the ovarian fluid pellet samples with high virus titers. Agius et al. $(1982,1983)$ and Dixon (1987) reported that factors inherent to kidney and other tissues inhibited viral infectivity in cell culture to a dilution of $1: 100$, and sometimes greater dilutions, of sample. We found this inherent inhibition occurred not only with kidney + spleen samples but also with ovarian fluid supernatant samples. Just as autointerference masked detection of high levels of infectivity, inhibitory factors associated with tissue and ovarian fluid supernatant masked low levels of infectivity and increased the potential for false negative results. Similarly, toxicity masked low levels of infectivity associated with kidney + spleen samples processed by trypsinization and with pyloric caeca processed by homogenization or trypsinization. The frequency of toxicity that we observed was comparable to that reported by Dixon (1987), but extended to greater dilu- tions of sample and was not relieved by removal of the inoculum. We also found greater toxicity associated with the trypsinization method than did Agius et al. $(1982,1983)$.

Our work shows that some samples collected by nondestructive means, ovarian fluid in particular, are suitable for detection of IPNV in asymptomatic fish and that, in general, factors associated with the clinical sample and processing method can affect percelved virus titer and prevalence. In this present study, the totality of the data, i.e. range of virus titers in concert with the levels of virus prevalence and levels of autointerference, toxicity, and inherent inhibition of infection, suggest that both populations of brook trout were heavily infected with IPNV. We are currently extending our study to determine if samples of sex products or other types of nondestructive samples will prove effective in detecting IPNV in brook trout that as a population carry low levels of virus.

Acknowledgements. We thank D. P. Anderson, L. A. Ford, R. L. Herman, E. D. Rockwell, and J. D. Teska for their review of the manuscript; D. E. Bowling and P. S. Whittington for technical assistance; and R. B. Owens for secretarial assistance. This research was supported in part by the U.S. Fish and Wildlife Service and in part by grant number $90-38500$ 5211 from the U.S. Department of Agriculture through the Northeastern Regional Aquaculture Center

\section{LITERATURE CITED}

Agius, C., Mangunwiryo, H., Johnson, R. H., Smail, D. A (1982). A more sensitive technique for isolating infectious pancreatic necrosis virus from asymptomatic carrier rainbow trout, Salmo gairdneri Richardson. J. Fish Dis. 5: $285-292$

Agius, C., Richardson, A., Walker, W. (1983). Further observations on the co-cultivation method for isolating infectious pancreatic necrosis virus from asymptomatic carrier rainbow trout, Salmo gairdneri Richardson. J. Fish Dis. 6: $477-480$

Amos, K. (ed.). (1985). Procedures for the detection and identufication of certain fish pathogens, 3rd edn. Fish Health Section, American Fisheries Society, Corvallis, OR

Dixon, P. F. (1987). Inhibition of infectious pancreatic necrosis virus infectivity by extracts of rainbow trout, Salmo gairdneri Richardson, tissue. J. Fish Dis. 10: 371-378

Hedrick, R. P., McDowell, T., Rosemark, R., Aronstein, D., Chan, L. (1986). A comparison of four apparatuses for recovering infectious pancreatic necrosis virus from rainbow trout. Prog. Fish Cult. 48: 47-51

Lannan, C. N., Winton, J. R., Fryer, J. L. (1984). Fish cell lines: establishment and characterization of nine cell lines from salmonids. In Vitro 20: 107-114

McAllister, P. E., Owens, W. J., Ruppenthal, T. M. (1987) Detection of infectious pancreatic necrosis virus in pelleted cell and particulate components from ovarian fluid of brook trout Salvelinus fontinalis. Dis. aquat. Org. 2: 235-237

McAllister, P. E., Schill, W. B. (1986). Immunoblot assay: a rapid and sensitive method for identification of salmonid fish viruses. J. Wildl. Dis. 22: 468-474 
Swanson, R. N., Gillespie, J. H. (1982). Isolation of infectious pancreatic necrosis virus from the blood and blood components of experimentally infected trout. Can. J. Fish. Aquat. Sci. 39: $225-228$

Wolf, K., Quimby, M. C. (1973). Fish viruses: buffers and methods for plaquing eight agents under normal atmosphere. Appl. Microbiol. 25: 659-664

Wolf, K., Quimby, M. C., Bradford, A. D. (1963). Egg associated transmission of IPN virus of trouts. Virology 21: $317-321$

Yamamoto, T. (1975a). Frequency of detection and survival of infectious pancreatic necrosis virus in a carrier population

Responsible Subject Editor: F. M. Hetrick, College Park, Maryland, USA of brook trout (Salvelinus fontinalis) in a lake. J. Fish. Res Bd Can. 32: 568-570

Yamamoto, $T$ (1975b). Infectious pancreatic necrosis (IPN) virus carriers and antibody production in a population of rainbow trout (Salmo gairdnen). Can. J. Microbiol. 21 $1343-1347$

Yamamoto, T., Kilistoff, J. (1979). Infectious pancreatic necrosis virus: quantification of carriers in lake populations during a 6-year period. J. Fish. Res. Bd. Can. 36: 562-567

Yu, K. K., Macdonald, R. D., Moore, A. R. (1982). Replication of infectious pancreatic necrosis virus in trout leucocytes and detection of the carrier state. J. Fish Dis. 5: 401-410

Manuscript first received: January 26, 1992 Revised version accepted: December 9, 1992 